\title{
ERRATUM
}

\section{Variations in tryptophan hydroxylase 2 linked to decreased serotonergic activity are associated with elevated risk for metabolic syndrome in depression}

S Kloiber, MA Kohli, T Brueckl, S Ripke, M Ising, M Uhr, A Menke, PG Unschuld, S Horstmann, D Salyakina, B Muller-Myhsok, EB Binder, F Holsboer and S Lucae

Molecular Psychiatry (2010) 15, 1123; doi:10.1038/mp.2009.8

Correction to: Molecular Psychiatry (2010) 15, 736-747; advance online publication 6 January 2009; doi: $10.1038 / \mathrm{mp} .2008 .142$
Following the online publication of the above article, the authors noted that the wrong version of Figure 2 was used. The correct version appears below:

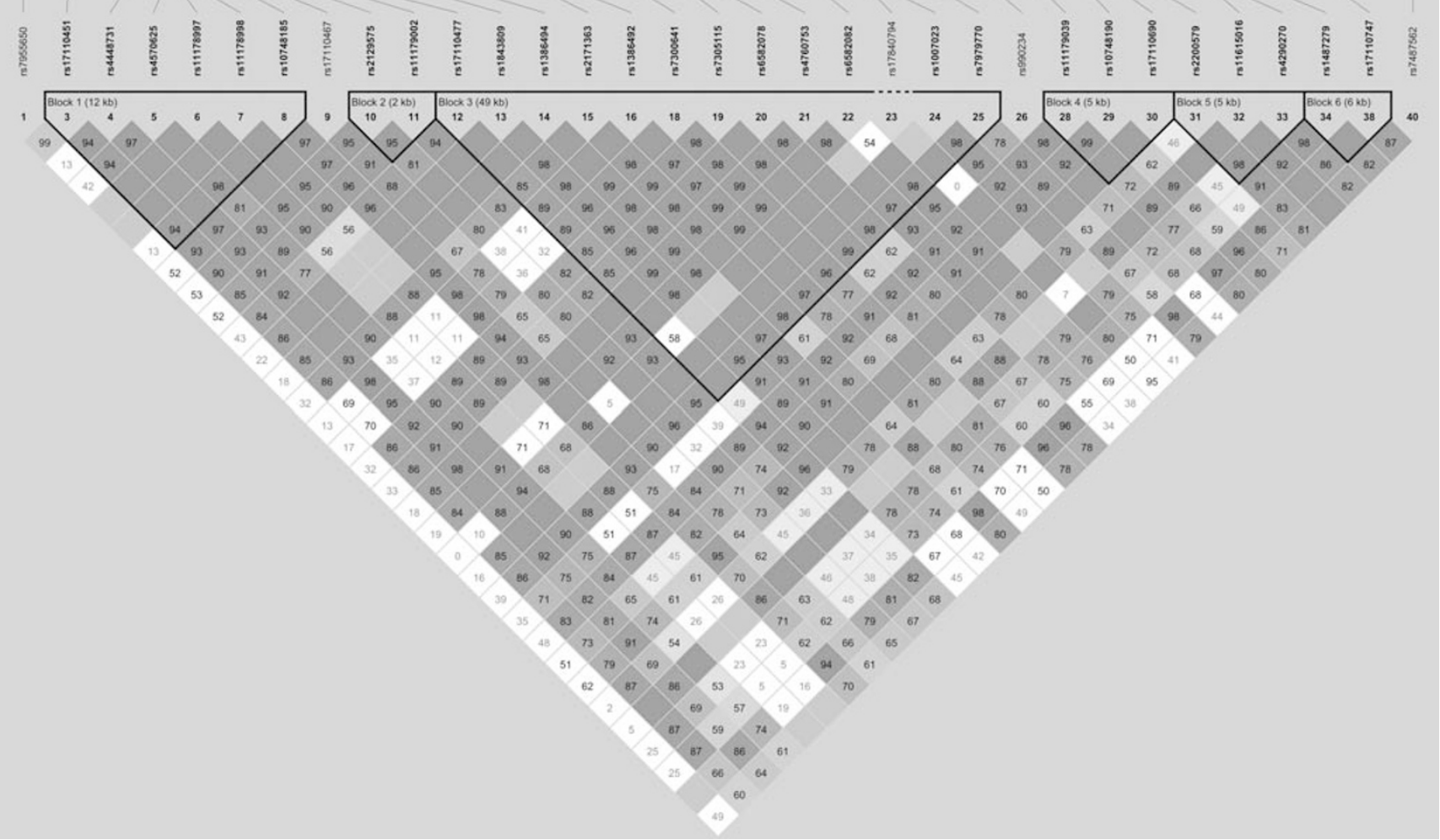

